\title{
THE SOCIAL CONSTRUCTION OF ORGANIZATIONAL LEARNING: \\ EXAMINING THE EPISTEMOLOGY OF MASTER DEGREE CURRRICULA
}

(Winner of the 2012 Management Education and Development Division Academy of Management Barry Armandi Award for Best Paper in Management Learning Research)

Daniel K. Dayton, PhD

The Chicago School of Professional Psychology

(C) Daniel K. Dayton, 2011 


\begin{abstract}
This is a phenomenological study of the communication processes around quality in a symphony chorus. Based upon intensive observations, interviews and participation in rehearsals and concerts over a five-month period, the study develops a narrative of the organization's endeavors to achieve quality musical performances. Data were analyzed via the theoretical construct of coordinated management of meaning theory using narrative, metaphor and episodic analysis. Individual and organizational understanding of the phenomena of communication about shared vision of quality were analyzed via organizational learning theory and complexity leadership theory, based upon phenomenological reduction analysis of participant interviews. Findings revealed relationships between level of academic degree of the study participants and their understandings of these phenomena. The findings indicated a bifurcation of ontological understanding between master degree holders and the understandings of either bachelor or doctoral degree holders, suggesting possible epistemological issues in master degree curricula.
\end{abstract}

\title{
Keywords
}

Organizational Learning, Epistemology, Social Construction, Phenomenology, Quality, Complexity Leadership Theory, CMM Theory 


\section{Introduction}

Behaviorist learning theories are deeply imbued with a positivistic ontological view of reality, in which the operative paradigm is that the learner (whether student or organizational member) must be externally motivated to learn (Pavlov, 1927; J. B. Watson, 1924) and that it is the responsibility of the master (whether teacher or organizational leader) to provide that motivation. Knowledge is presumed to be an object that can be passed on from master to learner via a structured set of lessons, and once properly motivated, the learner can attain and store such knowledge (Thorndike, 1923). Further, attainment of knowledge is presumed to be an objective goal that can be objectively measured, assessed, and refined (Skinner, 1957). The methodologies and terminologies of this philosophic stance reinforce the objective view of knowledgemethodologies are designed to modify behavior for the purposes of adaptation (Fiol and Lyles, 1985); terminology, such as retention and problem solving (Cyert and March, 1963), reflect the objectivist concept of cognition for the purposes of application alone. The etymology of the terminology of modern education systems reflects this objectivist philosophy in the names of the various levels of college degrees: bachelor, master, and doctor. Bachelor derives its etymology from the concept of young squire who has acquired sufficient retention of trivia and procedure to operate under the direction of a more seasoned master (American Heritage Dictionary, 2008). Master derives from the medieval concept of a master craftsman, who has achieved sufficient expertise in a field to operate independently, and to pass along the knowledge of process and procedure to apprentices (Kant, 1992). Doctor derives its etymology from the Greek term for teacher of philosophy, implying a level of instruction that surpasses the instruction in procedures of the master. Below the level of doctor, the instructional methodology is concerned with the what of learning, versus the why of learning.

Disaffected with the positivistic ontology, educational scholars (Duckworth, 1964, 1973; Piaget, 1955, 1961) began questioning the roles of both the teacher and the learner in the learning process, and thus developed a social-constructivist ontological view of learning. The socialconstructivist ontology remains focused, however, on the individual actions of the actors participating in the learning process, giving rise to learner-centered methodologies. Taking a more social-constructionist ontological view, organizational scholars (Argyris, 2000, 2003, 2006; Argyris and Schön, 1974, 1996; Fiol and Lyles, 1985; Senge, 2006) began the examination of the learning process itself as a socially constructed phenomenon, giving rise to learning-centered methodologies. Both of these methodologies attempt to address learning beyond the what of learning to include the how and why of the learning process. Because this study adheres to a socially constructed ontology of organizational learning, a more in-depth review of the literature of Chris Argyris and Donald Schön, and of Peter Senge is appropriate.

\section{Argyris and Schön}

In their analysis of the problems inherent to organizational learning, Argyris and Schön $(1974,1996)$ developed a theoretical model of organizational learning that distinguishes between what they termed single-loop learning and double-loop learning, and the action models in which they are employed, which they term model I theory-in-use and model II theory-in-use. Singleloop learning is characterized by the absorption and recitation of purportedly factual knowledge and the taking of action based upon that knowledge within a theoretical framework that is taken for granted. They represent a thermostat as example of single-loop learning - the thermostat absorbs knowledge about the temperature of the environment, compares it against the desired temperature settings, and takes action (either heating or cooling) based upon that comparison. At 
no point does the thermostat question the validity of the measured temperature or the desired temperature setting, or the decision-making rules. (One tragic example of single-loop learning in action is the actions that were taken by Nazi soldiers at internment camps during World War II, characterized by the admonishment, I was just following orders.) Double-loop learning is characterized by a process that examines the decision-making rules as well, so as to continually examine the underlying mental models by which it is constructed.

Model I theory-in-use employs single-loop learning based upon a strategy comprised of persuasion and rationality for the purpose of maximizing winning and minimizing controversy in communication. Argyris and Schön $(1974,1996)$ characterized the resulting processes as defensive, in which individual actors are compelled to be manipulative so as to protect their turf, and in which espoused theories, that is, what the actors say, is incongruent with their actions ( $D o$ as I say, not as I do) This defensiveness and incongruity leads to decision making that they define as self-sealing, with little to no examination of the underlying assumptions that bolster the decision processes.

Model II theory-in-use employs double-loop learning, based upon a strategy comprised of commitment to choice based upon the validity of knowledge for the purpose of defining and developing the best possible actions for organizational survival. Argyris and Schön $(1974,1996)$ characterized the resulting processes as authentic, in which individual actors are committed to the truth. The actions that are taken adhere to this commitment, resulting in more effective problem solving and decision making while minimizing the perceived need for individual protection of turf and defensive interpersonal interaction. Adherence to this commitment permits a continual examination of underlying assumptions forming the basis of decision making, with an understanding that such assumptions must be supported by evidence rather than tacit acceptance.

This study examined the communication processes that take place in the participant organization, and examined the underlying theory-in-use models that are employed. It included an examination of the nature of the communication and the extent to which strategic decision making employs double-loop versus single-loop learning.

\section{Senge}

Senge (2006) developed the concept of the learning organization, taking a systems perspective of the organization as a whole, rather than on the actions of the individuals within the organization. Much like the organizational learning theories developed by Argyris and Schön $(1974,1996)$, the systems theory of organizational learning is premised upon the concept of a continual reexamination of the assumptions regarding knowledge upon which decisions are based. Senge names this concept the fifth discipline, in which two significant mental shifts are required: "seeing interrelationships rather than linear cause-and-effect chains; and seeing processes of change rather than snapshots" (Senge, 2006: 73). Inherent to this circular view of causality is the requirement to examine the manner in which decisions made today affect the parameters of reality in the future, and will affect the decision making that must take place in the future as a consequence. This circular view of causality necessarily implies that a continual reexamination of reality and its inter-relational constructs is required for organizations not only to adhere to goals and objectives but also to continually test goals and outcomes.

Adopting such a circular view of causality is critical for organizations to break away from a paradigm of blame and finger pointing in which defense of previous decisions becomes paramount, and thus limits the free exchange of ideas. Under a systems view of organizational 
learning, the organization's vision is a superordinate guideline that directs organizational decision making rather than a mere goal that the organization sets out to achieve. Senge (2006: 143 stated, "It's not what the vision is, it's what the vision does." Exemplary of such a vision is the statement included in Procter \& Gamble's (2009: 5) vision, values, and purpose statement: "We will provide branded products and services of superior quality and value that improve the lives of the world's consumers, now and for generations to come." Such a vision provides an overarching decisional and behavioral guideline rather than an achievable goal that can be objectively measured.

A vision that presents a seemingly unachievable goal might appear to be a certain recipe for failure. However, in Senge's (2006: 143) view of systems thinking, such failure takes on a different connotation: "Failure is, simply, a shortfall, evidence of a gap between vision and current reality. Failure is an opportunity for learning." Mastering this view of vision requires a significant shift from the traditional mental models of communication and interaction that tend to defend the status quo, to a mental model that is open to the exchange of new ideas and recognized opportunities for learning rather than occasions for blame.

\section{Research Method}

The purpose of this study was to conduct a phenomenological analysis of the communication processes in the participant organization to address the research question, How do the communication processes in which organizational members engage support organizational learning that leads to a shared vision of quality? The epistemological reasons for conducting phenomenological research include a search for understanding specifically what the participants experienced, and how they felt during the phenomenon. Going beyond mere description of the shared experiences, the researcher brings an interpretation to the process by searching for discerning themes in the textual data so as to determine what the overarching commonalities are in that shared experience (van Manen, 1990). This is the critical element of the research, in that rather than merely describing the shared experiences of creating a quality staging of a symphonic choral composition, themes may arise central to the communication processes that lead to that creation.

In response axiological challenges associated with researcher bias, and in returning to the philosophical roots of phenomenological research, Moustakas (1994), and Stewart and Mickunas (1990) emphasize a bracketing of researcher experiences, which are then eliminated from the data analysis, so as to obtain a more purely participant collection of experiences. Their philosophical approach to phenomenological research rests on four pillars: "[a] A rejection of scientific empiricism, [b] a philosophy without presupposition, [c] the intentionality of consciousness, and [d] the refusal of subject-object dichotomy" (Creswell, 2007: 58-59).

The assumption central to phenomenological research arises from the operative paradigm that describing, coding, interpreting, and categorizing the shared experiences of the participants yield a deeper understanding of that phenomenon. Armed with this deeper understanding, it is presumed, those who work with participants of a particular phenomenon will be better prepared to render assistance, aid, recovery, or merely understanding of future participants. Alternatively, those who expect to experience a particular phenomenon may gain a deeper understanding of what they will face when confronted with or participating in that phenomenon. The nature of this study is phenomenological. The phenomenon of study is the communication process engaged by organization members when creating the construct of shared vision of quality, and how those communication processes are integral to the processes of organizational learning and leadership. 
The participants in the study are a symphony chorus comprised of 30 singers and instrumentalists, both professional and amateur musicians.

The sources of data were multiple: open-ended interviews with the study participants; observation of the interactions of the participants, during rehearsals, during administrative meetings, and during and after concert performances; and researcher participation in the process of rehearsing for and presentation of concert performances. The interviews were open-ended, semi-structured discussions about the participants' experiences with the organization as they told stories about recollections and perceptions of quality and how they communicated those experiences. The majority of the interviews were about an hour in length, although one was shorter at 45 minutes, and two were longer at 90 minutes and 120 minutes respectively. The interviews were transcribed by a professional transcriber into Word documents, which were then loaded into AtlasTi for coding. The transcripts were reviewed by each participant, all of whom attested to the accuracy of the transcriptions.

Because participants described their experiences using metaphors and metonyms, it was necessary to engage in metaphor analysis. For this portion of the analysis effort, the research drew from the work of Lakoff (1993, 2004), Lakoff and Johnson (1980/2003), and Lakoff and Turner (1989). In the analysis of the transcripts of the stories that the participants related, the research examined the cognitive and linguistic structure, situational effects of the metaphors used, and combining effects of metaphor on independent and complex phases and sentences. The metaphorical analysis gave rise to themes that literal analysis of the words and phrases that the participants use could not. Identification of conceptual cores and conceptual entities revealed the relational intricacies in the communication process between the conductor and the organizational members, as well as among the organizational members themselves. The grounding elements of the words and phrases used represented the anchors from which the concepts of quality and performance are shared among members.

Once the composite textural descriptions were developed, structural descriptions, and broader conceptual themes arising from the use of metaphor, the research then synthesized them into a model that provided both wide and deep understanding of the essence of the creation and communication of quality. That model provided a rich description of the experience of creating quality, as well as clues to understanding how those experiences may be effectively communicated in the social construction of a new reality grounded in a shared paradigm of quality and organizational learning.

\section{Results}

The means by which this section is organized is closely related to the tiers of Bloom's taxonomy as revised by Anderson and Krathwohl (2001). The subsections on thick description of the data collection process are characteristic of the understanding tier of the revised Bloom's taxonomy. Phenomenological reduction is characteristic of the applying tier, as the data were analyzed to develop major themes. The composite textural descriptions section is characteristic of the analyzing level of the taxonomy, as the themes were developed into networks representative of the organizational experience. The major findings section of the paper is characteristic of the evaluating tier of the taxonomy, wherein the synthesized thematic networks were evaluated using the theories of organizational learning (Argyris, 2006; Senge, 2006). Throughout this development the application of the theory of coordinated management of meaning (Pearce, 2007) was critical to the understanding of the organizational narrative. Finally, the section on discussion is characteristic of the creating tier of the revised Bloom's taxonomy, 
wherein the findings of this study become the foundations for suggesting new ways to scrutinize both management education and management practice, with proposals for research to engage that scrutiny.

Initial findings related to backgrounds of education and work. On the first review of the data collected via the interviews and observations, participant responses were analyzed vis-àvis their demographic characteristics of education and work. The demographics of the participants by education level and the general industry in which they earn livings are presented in Table 1. Because it is a volunteer organization, there is no requirement for members to hold a college degree to be accepted into the group. However, all of the participants of this study held at least a bachelor degree, and more than half also hold a master degree and/or a doctoral degree. Of the members who declined to participate, all four also hold a minimum of a bachelor degree. Also because of the volunteer nature of the organization, there is no requirement to be a professional musician or singer to be a member. In fact, of the participants, only five are professional musicians, with the rest working as professionals in a wide variety of fields. The fields of work are grouped by general industry for the purposes of grouping and simplification

Table 1. Participant Demographics: Education Level and Industry

\begin{tabular}{llc}
\hline \multicolumn{1}{c}{ Demographic } & \multicolumn{1}{c}{$N$} & \\
\hline \multirow{2}{*}{ Education level } & Bachelor degree & 10 \\
& Master degree & 6 \\
& Doctoral degree & 5 \\
Industry & Total & 21 \\
& Business & 6 \\
& Engineering & 2 \\
& Health science & 4 \\
& Law & 2 \\
& Music & 5 \\
& Religion & 2 \\
& Total & 21
\end{tabular}

The education levels of the participants became important because there arose from the data a significant bifurcation of interpretation of quality, communication, and leadership among the members divided between those who hold bachelor degrees and doctoral degrees versus those who hold master degrees. This bifurcation is discussed more fully in the section on Major Findings, and its implications are presented in the section on discussion. The relationships between industry and the areas of study (quality, communication, and leadership) did not appear to be quite so pronounced, with one notable exception. There was a significant bifurcation noted among the interpretations of those who are professional musicians and who hold a master of fine arts degree versus all the other participants.

\section{Themes Relating to Organizational Learning}

A crucial element of organizational learning in development of a shared vision among organizational members is creation of common understandings of the paths to achieve organizational goals. From the in-vivo codes that arose in the participant interviews, the data were analyzed again using thematic analysis to establish linkages among those in-vivo themes 
relating to elements of organizational learning. This analysis gave rise to three major themes: Communication, Nonverbal communication, and Emotional connection. Each of these major themes is discussed in the sections that follow:

Communication. The major theme of Communication arose from the participant interviews both as an in-vivo theme and as related to the in-vivo themes of emotional connection and learning styles. The participants tended to describe the process of interaction between themselves and the conductor, as well as interaction with other chorus members, in particular as they engaged in the process of learning the music, the stylistic interpretation, and the aesthetics. They described situations in which they relied on the dialogic engagement and exchange of knowledge to develop their individual understanding in relation to their own productive output, and to build upon a common understanding and production among all chorus members, so as to create an ensemble performance rather than dozens of simultaneous individual performances. Table 2 depicts the relationship between the major theme Communication and the in-vivo themes of Communication, Emotional connection, and Learning styles, with selected extracts from the participant interviews. In all, there were 131 instances in the data where these relationships arose.

Table 2. Major Theme Interview Extracts: Communication

\begin{tabular}{ll}
\hline \multicolumn{1}{c}{ In-vivo theme } & \multicolumn{1}{c}{ Interview extract } \\
\hline Communication & $\begin{array}{l}\text { How he wants it would have to be communicated and then I'd have to make the } \\
\text { notes and make the adjustments because I probably learned it the other way. }\end{array}$ \\
$\begin{array}{l}\text { Emotional } \\
\text { connection }\end{array}$ & $\begin{array}{l}\text { It was taking the pauses to acknowledge that everyone is doing the emotional } \\
\text { things and the personal things necessary to achieve the big outcomes. }\end{array}$ \\
Learning styles & $\begin{array}{l}\text { See, I have a hard time - unless I'm hearing it, I have a hard time understanding } \\
\text { it. Visual doesn't turn me on as much as hearing something. }\end{array}$ \\
\hline
\end{tabular}

In order for the chorus members to begin to develop their individual understandings of the meaning of the music and the intentions of the composer, the conductor needed to be cognizant of the varied learning styles of the chorus members so as to incorporate varied approaches to facilitating that understanding. Some of the chorus members tend to learn more visually, and for them the key elements are translating the musical notations and their own markings into the elements of their own performance, especially as it relates to the overall ensemble performance. Others tend to learn more aurally, relying upon what they hear both from the explanations of interpretation from the conductor and what they hear during the musical rehearsals. Others tend to learn more kinesthetically, and rely upon interpretation of the movements and signals from the conductor into their own physical feelings and movements.

Without connection to these learning styles, the process of developing emotional involvement among the chorus members would be problematic. Further, emotional connection among the chorus members seems to facilitate the communication process, especially with regards to the ensemble performance. Because choral music is more emotionally understandable to the audiences when the performance is as an ensemble rather than as a collection of individual 
singers, the success of achieving an overall outcome of quality performance is dependent upon that emotional connection.

Emotional connection. The production of music is, in and of itself, an expression of human communication that is steeped in emotion. Instrumental musical compositions can express intense emotions, and evoke similarly intense emotional reactions among listeners. Choral musical compositions possess the added dimension of actual verbal expression of those emotions, and thus can evoke even stronger and more unified emotional reactions among the listeners. Achieving that emotional connection with the listener necessarily requires emotional connection from the performers. In a chorus, that connection is achieved when the emotional expression is organizational rather than merely individual, and thus is a crucial element of organizational learning. This theme arose among nearly all of the participants. Among the invivo themes that relate to the major theme of Emotional connection were Emotional experience, Emotional engagement, and Emotional expressiveness, as indicated in Table 3.

Table 3. Major Theme Interview Extracts: Emotional Connection

\begin{tabular}{ll}
\hline \multicolumn{1}{c}{ In-vivo theme } & \multicolumn{1}{c}{ Interview extract } \\
\hline Emotional experience & $\begin{array}{l}\text { And behind that is often, you know, well, I don't want to say often, } \\
\text { but emotion is . . and I think you have to be in tune with that. You } \\
\text { have to be experiencing it as you're trying to communicate that. }\end{array}$ \\
Emotional engagement & $\begin{array}{l}\text { And I was familiar with that from a girl who sang in an opera } \\
\text { workshop, I mean, you were in tears because she just, she felt-you } \\
\text { could tell she was feeling it. Vocally, she was okay, but she was } \\
\text { feeling it and you were moved by it. Well, when we went to see the } \\
\text { professional thing and the whole thing was just like, yuck, I said, }\end{array}$ \\
$\begin{array}{l}\text { Finally, here's . . and this woman, she could have been singing the } \\
\text { phone book as emotionally attached as she was. It was horrible. It } \\
\text { was like blah, blah, whatever. It was so un-engaging. }\end{array}$ \\
$\begin{array}{l}\text { Yes, it has to be. It has to be well done in terms of expressiveness, in } \\
\text { terms of accuracy, but then it reaches beyond the intellect and it goes } \\
\text { into the emotions, which I think music is intended to do. And there } \\
\text { was another performance and I think this one was at Anderson Hills; } \\
\text { it was a religious number and it was probably the most emotional } \\
\text { performance in which I participated. The music, what we were } \\
\text { singing, just touched me so much. }\end{array}$
\end{tabular}

Even when a live musical performance is technically perfect, if it lacks personal emotional experience and expressiveness by the performer, it is likely to fail to engage emotionally with the audience. For the chorus to develop and present a unified ensemble performance that effectively created this emotional connection, the process of organizational learning is requisite to ensuring a common shared vision among the members of the chorus.

\section{Composite Textural Descriptions}

Phenomena such as communication, learning, leadership, and quality may characterized as discrete events, or they may be characterized as constructs of social interaction among people 
who experience them. This study takes the latter approach, in which these phenomena are analyzed from the perceptions of the organizational members who experience them as individuals, and then constructed into a composite that more fully represents the holistic organizational experience. The perceptions are drawn from the themes that were developed from the participant interviews and from observations of rehearsals and concerts over the 5-month period of the study related to organizational learning, and are presented in Table 4.

Table 4. Phenomenon of Learning Themes

\begin{tabular}{ll}
\hline \multicolumn{1}{c}{ Theme } & \multicolumn{1}{c}{ Is related to the intra-organizational question } \\
\hline Verbal communication & $\begin{array}{l}\text { What do we discuss and how do we incorporate that into our musical } \\
\text { performance? How do we come to agree? }\end{array}$ \\
Nonverbal communication & $\begin{array}{l}\text { What cues do we agree upon so that during performances we are } \\
\text { expressing that to which we agreed? }\end{array}$ \\
Emotional connection & $\begin{array}{l}\text { What does the music mean to us emotionally? How do we come to } \\
\text { agree to express that emotion? }\end{array}$ \\
\hline
\end{tabular}

The phenomenon of learning (Table 4) is experienced among members of the participant organization as a construct of the themes of verbal communication, nonverbal communication, and emotional connection to the meaning of the music. Verbal communication takes place during the rehearsals, and the members of the chorus discuss and share knowledge and ideas about the music itself, and as they work out systems by which that verbal communication can be translated into the nonverbal communication that takes place during the concert performances. There is significant linkage between the verbal exchange and the nonverbal exchange, which ultimately become a complex set of visual and auditory cues to manage communication during the concert to effectively convey the emotional content and context of the music.

The learning process is multifaceted, comprised of intellectual and emotional understanding of the meaning of the music and the composers' intentions, and developing and managing visual and auditory signals that convey a wealth of meaning about which a common understanding has been developed during rehearsals. The phenomenon of learning is the fundamental shared experience by which the members of the organization not only come to agree upon what they know of their productive output but also share that knowledge with the audience.

\section{Major Findings}

In order to develop the major findings of this study, the final step in the analysis was to build further upon the composite textural descriptions of the phenomena to develop the composite structural descriptions, which depict not only the essence of the participant experiences but also the relationships among a variety of factors to develop an overall organizational understanding of the phenomena. Because the organization consists of numerous individuals, all of whom personally experience phenomena through their own lenses of experience, education, and background, the essence of the organizational experience tends to 
cover ranges of understanding and ontology. The structure of those ranges may be understood by synthesizing individual participant attributes with the textural descriptions of the phenomena, and then examining the relationships among those attributes and the ranges of experience. For this study, there were five major findings among the phenomena of communication, learning, and quality, for which the attributes of education level and tenure with the organization had effects upon individual experiences, creating ranges of organizational experience. The construction of this study was not of the nature to discern the strengths of these relationships or to explain why these relationships exist. It could be the topic of future studies to validate these relationships and once validated, to determine the nature of the correlation, and perhaps even to attribute causes to its existence. Those major findings are discussed in the subsections that follow.

\section{Findings Related to Organizational Learning}

There was one major finding related to organizational learning, and it was based upon the attributes of the participants with regard to education level. From the descriptions of the participants, there arose a significant bifurcation between the concept of learning as an individual process versus learning as an organizational process. That bifurcation tended to be most significantly related to the education level of the participant describing the phenomenon, and is presented in Figure 1.

Figure 1. Bifurcation of focus on learning by degree level.

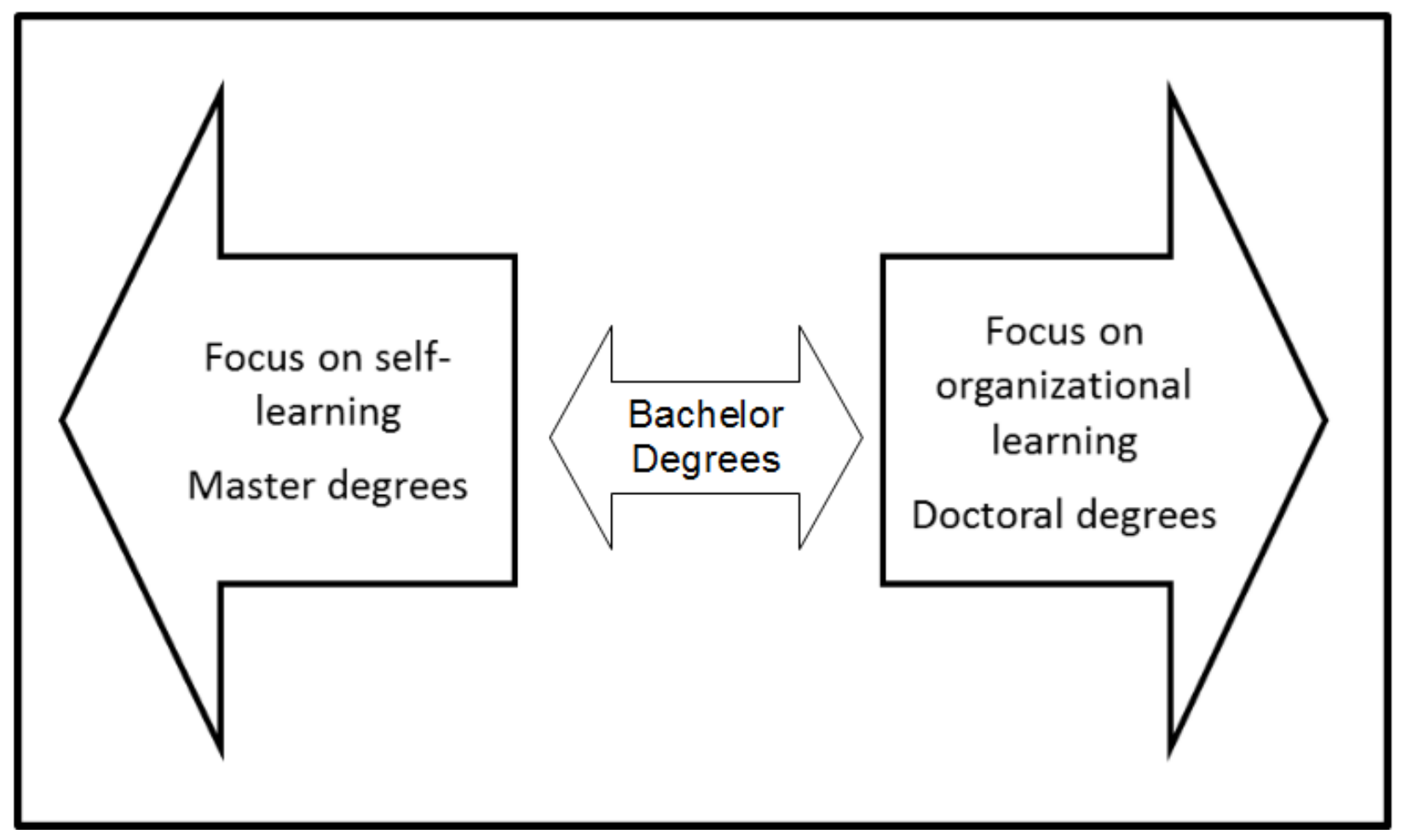

Participants with master degree tended to describe the phenomenon of learning only at the individual level, and with a heavy reliance upon their own personal knowledge by which to gauge both their understanding of the meaning of the music and to accommodate their individual 
performance to the directions of the conductor. They tended to avoid open discussion with other members of the organization with regard to that learning, even though they devoted significant thought to the process. They tended to apply their own knowledge of musical performance and of organizational issues to their understanding, internalizing the learning process and reluctant to engage in dialogue about it.

Participants who held doctoral degrees tended to view the learning process as highly dynamic and fluid, with open interchange of ideas among members of the organization, often not only offering significant input but also willing to accept and incorporate alternative points of view. Their focus was not on their own learning, but rather on the learning of the organization as a whole.

Somewhat surprisingly, the participants holding bachelor degrees tended to fall in the middle of the bifurcation between individual learning and organizational learning. They tended, however, to view the individual learning process as one in which they were the recipient rather than the contributor to learning. Interestingly, they still described learning phenomena in organizational terms as well, as if their own understanding of the phenomenon of learning were bifurcated. The bifurcation was not between different individuals holding bachelor degrees, but rather was from within the individuals themselves.

The division between understanding the phenomenon of learning as either an individual process or as an organizational process was sharp, with master-degree holders falling on the side of individual learning and doctoral-degree holders falling on the side of organizational learning. Bachelor-degree holders had divided understanding, which although seemingly contradictory, demonstrates an openness to organizational communication that master-degree holders have somehow lost and that doctoral-degree holders have regained.

\section{Discussion}

One reason that this study was undertaken includes a growing dissatisfaction among management practitioners with the methodologies derived from these positivist-rationalist and social-constructivist theories. Methodologies arising from the theories of Taylor (1911, 1947/1967), Juran (1951, 1962), and Deming (1986) such as TQM and Six-Sigma have generally failed to achieve success in practical efforts to achieve quality output from organizational processes. Practices that have attempted to engage these methodologies in organizational learning, such as those of Schroeder et al. (2008), with a social-constructivist view of individual learning, have not achieved success in achieving an organizational shared vision. Popular leadership books have been of questionable effectiveness.

A second reason that this study was undertaken was to take a social-constructionist view of the processes of learning and the communication processes that are created as a phenomenon unto itself, rather than as an organizational output. Hence, the social-constructionist organizational learning theories of Argyris and Schön (1996) and Senge (2006) were the basis of analysis that viewed learning and leadership as processes rather than outcomes. The communication among organizational members in constructing the processes of learning and leadership were viewed also as processes, rather than outcomes, via the social-constructionist CMM theory of Pearce (2007) and Pearce and Cronen (1980). The purpose was to develop an analysis of these processes as socially constructed phenomena, so as to gain an understanding of their interrelationships in an organizational quest for a shared vision of quality. 
Finally, this study was conducted with a nonprofit, performing arts organization so as to minimize the temptation to attempt to objectively identify exemplars of quality output or rationalistic measures of efficiency. By conducting the study with a performing arts organization, it was possible to focus on the phenomenon of communication about quality without the distractions of objective measures of quality or of decreasing costs and increasing profit margins. The results of the data collection provided a rich basis for examining the processes that support communication about quality as a phenomenon unto itself and the analysis of those data provide findings that lend insight into engendering its creation. The next section presents a summary of the findings of that analysis.

\section{Summary of Findings}

There were three significant findings that arose from the analysis of the data collected during this study: two findings related to the nature of the communication processes and one finding related to the nature of process of organizational learning. The findings were based upon in-vivo descriptions of participant experiences with the organization, and the relationships of the nature of those descriptions based upon participant attributes of education level and tenure with the organization. The demographic makeup of the participants, which represented more than $80 \%$ of the available population of the organization, was relatively homogeneous. All participants were well-educated, middle- and upper middle-class Americans who share similar demographics of age, religion, and employment status. Even so, there were remarkable differences in the participants' descriptions of the essences of communication, learning, and quality attributable to differences in education level and tenure with the organization.

Participants holding master degrees tended to describe either nonexistent or dialectic processes of communication; participants holding bachelor degrees tended to describe communication processes that were largely dialectic but bordering on dialogic; and participants holding doctoral degrees tended to describe communication processes that were largely dialogic and, to a degree, organizationally holistic.

Participants whose tenure with the organization was the shortest, from 1 to 3 years, had either a tendency to refrain from participation in communication or to describe communication as a dialectic process. Participants whose tenure with the organization was in the middle, from 4 to 10 years, were more likely to describe communication processes that were dialogic, but retained a certain degree of understanding that reflected a dialectic process. Participants whose tenure with the organization was the longest, over 10 years, were more likely to describe communication processes that were dialogic and even organizationally holistic, an understanding that was absent from all less-tenured members of the organization.

With regard to organizational learning, there was a stark contrast between the descriptions of participants holding a master degree versus those holding either a bachelor degree or a doctoral degree. Participants holding a master degree tended to describe learning that was a purely individual process, with intent focus on their own faculties and learning background. Participants holding a doctoral degree were most likely to describe learning in an organizational context, with a focus on how the organizational learning contributes to a shared vision among members of how to achieve quality performances. Participants holding bachelor degrees also tended to describe learning as an organizational process, however, their descriptions also tended to be less philosophical than the doctoral-degree holders. When the bachelor-degree holders described their own individual learning, it was most often in the context of contribution to the 
organizational whole, whereas among the master-degree holders, the individual learning descriptions tended to be more self-focused.

\section{Discussion of Findings}

It is important to reemphasize that this was a phenomenological study, and that as such, it does not venture to hypothesis-test the correlations among the relationships in the findings. Nor does it attempt to discern the causality of those relationships. Those efforts may be the endeavors of future studies. However, the findings do indicate the existence of fascinating relationships in an organization among the demographics of its members and the communication processes they employ to develop their understandings of such organizational facets as leadership, learning, and the quest for quality production.

The findings of this study may present a basis for understanding why it is that so many organizational undertakings of TQM and Six-Sigma fail. It is clear from the data divulged by this study that among the most important aspects of human organizational endeavors to achieve quality production is emotional engagement of the members of that organization. Development of a shared vision, engagement in double-loop learning processes, and episodes of communication require, at the least, an awareness of the emotional aspects of human existence and organizational membership. Shared visions are not developed in the absence of emotional awareness; double-loop learning requires an intelligence of the defensive emotions of model I thinking in order to overcome them; and human communication is replete with emotional attachment as people engage in speech acts and construct their own narratives of communication episodes. TQM and Six-Sigma, as purely rationalistic frameworks, deny the existence of emotion. Denial of a vastly significant component of human existence in organizational endeavors dooms purely rationalistic engagements to failure, or worse, creation of soulless organizations. Understanding of this phenomenon is by no means uniquely revealed by this study, and has been the source material for innumerable tales from the arts. Creation of a purely rationalistic society was typified in the Star Trek episode "Return of the Archons," in which Commander Spock remarked, "This is a soulless society, Captain. It has no spirit, no spark. All is indeed peace and tranquility - the peace of the factory, the tranquility of the machine. All parts working in unison" (Roddenberry \& Pevney, 1967). Still, business scholars continue to advocate quashing of emotional aspects of organizational engagement in pursuit of goal attainment and purely rationalistic motivation. Lindenberg and Foss (2011: 511) advocated the use of negative sanctions and relegation of emotional rewards as a means to accomplish organizational goals: "Negative sanctions (financial or symbolic) for not contributing are likely to be legitimate in a context of joint production and will strengthen a normative goal frame. . . . Hedonic [emotional] goals should be kept in the background." The results of this study raise significant doubt regarding that conclusion.

The findings also raise some intriguing questions regarding the nature of university education at the master-degree level and its potential impact upon the ability of organizations to engage in adaptive and emergent leadership processes, genuine organizational learning, and socially productive communication processes. Recent research has proposed that the current time is critical for the engagement of emotional awareness and emotional intelligence not only in business but also in MBA programs. McTiernan and Flynn (2011: 323) surmised that there is brewing a "perfect storm" for elevating more women, who possess heightened emotional awareness and intelligence than men, to positions of deans of business schools. Although this study does not focus specifically on the emotional content (or lack thereof) of master-level 
education, it presents evidence of a dearth of emotional awareness among those who possess master degrees.

Further, whereas the impacts of tenure have been thoroughly studied vis-à-vis such topics as job performance ( $\mathrm{Ng}, 2010$; Simsek, 2007), job satisfaction (Galle and Lawrence, 2011; Lovett, Hardebeck, Coyle, and Torres-Solis, 2006), socialization (Juenke, 2005; Rollag, 2004), and reasoning (Hambrick, 1991; Pennino, 2002), no studies to date have examined the relationship of member tenure and organizational learning. The results of this study call for a deeper body of research into the effects of tenure among rank-and-file organization members, particularly in light of the spate of downsizing efforts among business organization over the last two decades. The following subsections discuss the findings in all of these areas through the lenses of complexity leadership theory (Uhl-Bien et al., 2008) and organizational learning theory (Argyris, 2006; Argyris and Schön, 1996; Senge, 2006), and present those questions.

\section{Organizational Learning Theory}

Inherent to the development of a shared organizational vision (Senge, 2006) are communication processes in which organizational members engage to co-construct that vision. Argyris and Schön (1996) theorized that the nature of those communication processes, which they labeled single-loop learning (model I theory) and double-loop learning (model II theory), can either emasculate or facilitate that co-construction. In single-loop learning, organizational defensive routines prevent the questioning and examination of assumptions central to those routines and processes, and tend to be self-reinforcing in support of their closed systems of process. Argyris (2006) characterized this type of closed system as a management trap, one that reinforces existing routines and stifles learning, thereby being incapable of supporting emergent change.

In double-loop learning, the organizational defensive routines are brought into the light of examination and question, so that when organizations are met with crisis situations, they can avoid self-reinforcing patterns of action that wreak organizational havoc. This type of continual self-reexamination is the antithesis of traditional theories of organization, in which the overarching purpose is to establish and defend methods and routines of proven stability. Unfortunately, in a world rife with increasingly complex environmental, political, and competitive challenges, a quest for stability may be mythic. Double-loop learning, rather than seeking a static level of stability or equilibrium, engenders organizational flexibility to adapt to those challenges as they emerge. In a system of double-loop learning, management is not an oracle of organizational wisdom, but rather becomes the facilitator of organizational dialogue.

In the findings of this study, it is evident that members whose tenure with the organization is the shortest tended to offer descriptions of learning most characteristic of singleloop learning. This, perhaps, should not be a surprise, because as the newest members of the organization, they have no foreknowledge of the organizational routines that exist. They take the first few years to learn the organizational routines. The members whose tenure is in the middle offered descriptions of learning in which they begin to feel more comfortable with questioning and discussing those routines, and in engaging in dialogue about learning as an organizational entity rather than an individual endeavor. The longest-tenured members of the organization were most likely to offer descriptions of learning characterized by the tenets of double-loop learning, and were most comfortable engaging in organizational dialogue that challenged organizational routines. 
This raises serious questions regarding the viability of double-loop learning in organizational environments in which the average tenure of workers is 4.4 years and the average tenure of managers is 6.1 years. What is it about our systems of employment that generate such short organizational tenures, and are those systems preventing organizations from engaging in emergent change in response to environmental, political, and competitive stresses? Can organizational members whose tenure has barely provided sufficient time to learn organizational routines be expected to engage in dialogue that challenges those routines? Is it reasonable to expect that CEOs can engage organizations in dialogic, double-loop learning processes with average tenures of only 6.1 years? These questions could form the basis for further studies. Such studies might show that these characteristics are particular to the participant organization alone, or they may divulge a general pattern among organizations at large. If those patterns emerge, then studies could be devised to examine the strength of correlation, and if sufficiently strong, to understand why these patterns exist, and further, to understand how they may be thwarted.

Similar questions arise from the finding that educational level has a relationship with the way in which the members view the learning process. Doctoral- and bachelor-degree holders were more likely to engage in dialogue about that process, whereas master-degree holders tended to hold to single-loop learning processes. What is it about master-degree programs that encourage their graduates to believe that they now possess unshakeable knowledge, and to refrain from engaging in organizational processes that examine and challenge that knowledge? Is this phenomenon a peculiar characteristic of members of the participant organization, or is it a phenomenon that exists more generally? If it exists more generally, is it desirable? Should educators reexamine the epistemology of master-degree programs to include engagement in the knowledge creation process, rather than as repositories of existing patterns of knowledge? Researchers may wish to engage these questions in future studies.

\section{Conclusions}

This phenomenological study, addressing the research question, How do the communication processes in which organizational members engage support organizational learning that leads to a shared vision of quality? is singular in its research construct, examining organizational communication processes through the lenses of the organizational learning theories of Argyris (2006) and Argyris and Schön (1996) and complexity leadership theory (UhlBien et al., 2008). The findings of the study reflect seldom-explored connections among education level and tenure among organizational members in the construct of their communication processes about leadership and quality.

Although it would be irresponsible to draw generalized conclusions from this phenomenological study, the complexity of the processes by which organization members engage in learning and by which they develop shared visions of quality would appear to be influenced by factors that have not been previously addressed. It also revealed that single-loop and double-loop learning processes can exist in an organization simultaneously, reflecting added complexity in sustaining genuinely adaptive learning processes. Further, the study lends support for the construct of complexity leadership theory, which is still in its development stages. Finally, the study provides support for the use of coordinated management of meaning theory (Pearce, 2007; Pearce and Cronen, 1980) for examining the communication processes in which organization members engage as they develop common understandings of their joint efforts.

The findings of the study revealed surprising relationships among organizational tenure and member education level with their perceptions of communication processes taking place in 
the organization, with their understanding of the learning processes in organizations, and with concepts of leadership within the organization. It also revealed the importance of emotional connection among organizational members to those processes in the organizational quest for quality. Heightened emotional connection appeared to be related to the genuine development of a shared vision of that quality, whereas emotional detachment appeared to be related to single-loop learning and defense of organizational routines.

\section{Implications and Applications}

The implications of this study branch in three directions. First, the traditional methods by which managers endeavor to engage organization members are called into question. Emotional engagement, which this study shows to have a marked relationship to learning, leadership, and communication processes, is rarely addressed in those traditional methods, with the exception of forestalling the emotions of fear and doubt. This is especially true in change management methods and efforts, and may be an indication of the general failure of implementations of quality efforts via purely rational methods such as TQM and Six-Sigma. This study reveals that a far wider range of emotional involvement is engaged via the socially constructed communication processes that support organizational learning and leadership, and that engagement of those emotions is a critical element of developing a shared vision among organization members.

Second, although length of service or tenure has been addressed many times, both with regards to such concepts as institutional knowledge and to organizational dynamics, this study may be among few that depict the range of development of the communication processes from new members to those who have been with the organization for decades. In an age when quests for organizational efficiency often translate into layoffs and early retirements, that which is decried is the loss of institutional knowledge. Is it possible that the very efforts to create organizational quality through downsizing actually lead to a self-destructive process in which the loss of institutional knowledge accelerates organizational demise? Are those efforts entrapped in cycles of single-loop learning that serve only to reinforce the organizational defensive routines that lead to the difficulties in the first place? If so, then there needs to be a reexamination of methodologies for engaging organizations in more constructive pursuits of quality, those that leverage the socially constructed knowledge of its longer-tenured members into efforts to engage the entire population of the organization.

Third, the relationship between level of education and epistemology bears closer examination. If future studies reveal similar relationships between a master-degree level of education and epistemologies that ignore the socially constructed nature of knowledge and the importance of emotional engagement, the implications of that relationship require further examination. If master-degree graduates are those who would lead organizations and yet are unable to acknowledge the socially constructed processes of adaptive and emergent leadership and of double-loop learning, then what is the hope that organizations at large can deal effectively with environmental, regulatory, and competitive stresses? There has been a hue and cry regarding the relevancy of MBA education among scholars and practitioners; is that hue and cry fueled by the very epistemology that forms the basis of that education?

This study does not purport to offer applications to deal with these questions. Rather, it serves to point the direction toward further research, specifically to validate the relationships that have been discovered here. The implications revealed in this study of the relationships of emotional engagement and epistemological understanding of socially constructed processes 
could be far-reaching. The next and final section offers some suggestions for the possibilities of that future research.

\section{Recommendations for Further Research}

The findings suggest that there are many more avenues of research needed to shed additional light on those processes. First, additional phenomenological or ethnographic studies of organizations employing social-constructionist theories could serve to discover similar findings among organizations other than the one involved in this study. The findings of this study may well be peculiar to the participant organization, and therefore, although interesting, completely inapplicable to any other organization. However, to make that determination, there should be further studies of other organizations in which the communication processes related to quality are closely examined and classified. Such future studies may reveal that the participant organization is unique, or they may discover similar relationships; such future studies may reveal relationships that this study did not address. However, the implications of additional studies revealing similar findings about communication processes, organizational learning, and leadership as a socially constructed process of interaction in a complex dynamic system could lead to a revolution of communication and leadership theories, and could lead, finally, to a socially constructed theory of organizational learning.

Should further phenomenological studies of the communication processes in organizations reveal similar relationships, then the statistical significance of those relationships and outcomes of organizational success (or failure) should be tested. Individual case studies could be developed from examination of those processes in other organizations, from which meta-analyses could reveal cross-functional and cross-industrial similarities (or differences). Such studies could serve as the basis for reexamining the epistemological nature of masterdegree programs in the organizational fields, from which additional studies of management education could be developed.

The findings of this study are compelling; they raise many questions about existing quality improvement methodologies as well as theory and practice of organizational communication, leadership, and learning. Let this study be the basis for future research that provides a foundation for development of management methods that account for the socially constructed nature of quality. 


\section{REFERENCES}

Anderson, L and Krathwohl, DA (2001) Taxonomy for learning, teaching and assessing: A revision of Bloom's taxonomy for educational objectives. New York, NY: Longman.

Argyris, C (2000) Flawed advice and the management trap: How managers can know when they're getting good advice and when they're not. England: Oxford University Press.

Argyris, C (2003) A life full of learning. Organization Studies, 24(7): 1178-1192.

Argyris, C (2006) Reasons and rationalization: The limits to organizational knowledge. England: Oxford University Press.

Argyris, C and Schön, D (1974) Theory in practice: Increasing professional effectiveness. San Francisco, CA: Jossey-Bass.

Argyris, C and Schön, D (1996) Organizational learning II. Reading, MA: Addison-Wesley.

Creswell, JW (2007) Qualitative inquiry and research design: Choosing among five approaches (2nd ed.). Thousand Oaks, CA: Sage.

Cyert, RM and March, J G (1963) A behavioral theory of the firm. Englewood Cliffs, NJ: Prentice-Hall.

Deming, WE (1986) Out of the crisis. Cambridge: Massachusetts Institute of Technology, Center for Advanced Engineering Study.

Duckworth, ER (1964) Piaget rediscovered. Journal of Research in Science Teaching, 2(3): 172175.

Duckworth, ER (1973) Language and thought. In M. Schwebel, \& J. Ralph (Eds.), Piaget in the classroom. New York, NY: Basic Books, 258-277.

Fiol, CM and Lyles, MA (1985) Organizational learning. Academy of Management Review, 10(4): 803-813.

Galle, WP and Lawrence, H (2011) Tenure, status, and workload: Fundamental issues among business communication faculty. Journal of Business Communication, 48(3): 319-343.

Hambrick, DC (1991) The seasons of a CEO's tenure. Academy of Management Review, 16(4): 719-742.

Juenke, EG (2005) Management tenure and network time: How experience affects bureaucratic dynamics. Journal or Public Administration Research and Theory, 15(1): 113-131.

Juran, JM (1951) Quality control handbook. New York, NY: McGraw-Hill. 
Juran, JM (1962) Quality control handbook (2nd ed.). New York, NY: McGraw-Hill.

Kant, I (1992) The conflict of the faculties (Mary J. Gregor, Trans.). Lincoln: University of Nebraska Press.

Lakoff, G (1993) The contemporary theory of metaphor. In A. Ortony (Ed.), Metaphor and thought (2nd ed.). New York, NY: Cambridge University Press, 201-251.

Lakoff, G (2004) Don 't think of an elephant! Know your values and frame your debate. White River Junction, VT: Chelsea Green.

Lakoff, G and Johnson, M (1980/2003) Metaphors we live by. IL: University of Chicago Press.

Lakoff, G and Turner, M (1989) More than cool reason: A field guide to poetic metaphor. IL: University of Chicago Press.

Lindenberg, S and Foss, NJ (2011) Managing joint production motivation: The role of goal framing and governance mechanisms. The Academy of Management Review, 36(3): 500525.

Lovett, S, Hardebeck, S, Coyle, T and Torres-Solis, JR (2006) Job satisfaction and organizational tenure in three Mexican assembly plants. Journal of Applied Management and Entrepreneurship, 11(1): 36-65.

McTiernan, S M and Flynn, PM (2011) "Perfect storm" on the horizon for women business school deans? Academy of Management Learning and Education, 10(2): 323-339.

Moustakas, C (1994) Phenomenological research methods. Thousand Oaks, CA: Sage.

Pavlov, IP (1927) Conditioned reflexes: An investigation of the psychological activity of the cerebral cortex. London, England: Oxford University Press.

Pearce, WB (1989) Communication and the human condition. Carbondale/Edwardsville: Southern Illinois University Press.

Pearce, WB (2007) Making social worlds: A communications perspective. Malden, MA: Blackwell.

Pearce, WB and Cronen, VE (1980) Communication, action, and meaning. New York, NY: Praeger.

Pennino, CM (2002) Does tenure impact upon the principled reasoning of managers? Journal of Business Ethics, 40(3): 219-226.

Piaget, J (1955) The child's construction of reality. London, England: Routledge/Kegan Paul.

Piaget, J (1961) La psychologie de l'intelligence [The psychology of intelligence]. Paris, France: Armand Colin. 
Procter \& Gamble Company (2009) Annual report. Cincinnati, OH.

Roddenberry, G (Producer/Executive Producer) and Pevney, J (Director) (1967) Return of the Archons [Television series episode]. In Star trek. Los Angeles, CA: Paramount Studios.

Rollag, K (2004) The impact of relative tenure on newcomer socialization dynamics. Journal of Organizational Behavior, 25(7): 853-872.

Schroeder, RG, Linderman, K, Liedtke, C, and Choo, AS (2008) Six-Sigma: Definition and underlying theory. Journal of Operations Management, 26(4): 536-554.

Senge, PM (2006) The fifth discipline: The art and practice of the learning organization (2nd ed.). New York, NY: Doubleday.

Simsek, Z (2007) CEO tenure and organizational performance: An intervening model. Strategic Management Journal, 48(3): 653-662.

Skinner, BF (1957) Verbal behavior. Acton, MA: Copley.

Stewart, D and Mickunas, A (1990) Exploring phenomenology: A guide to the field and its literature. Athens: Ohio University Press.

Taylor, FW (1911) The principles of scientific management. New York, NY: Harper Brothers.

Taylor, FW (1947/1967) The principles of scientific management. New York, NY: Norton.

Thorndike, EL (1923) Educational psychology. London, England: Routledge/Kegan Paul.

Uhl-Bien, M (2006, December) Relational leadership theory: Exploring the social processes of leadership and organizing. The Leadership Quarterly, 17(6): 654-676.

Uhl-Bien, M, and Marion, R (Eds.) (2008). Complexity leadership: Part I: Conceptual foundations. Charlotte, NC: Information Age.

Uhl-Bien, M, Marion, R, and McKelvey, B (2008) Complexity leadership theory: Shifting leadership from the Industrial Age to the Knowledge Era. In M Uhl-Bien and R Marion (Eds.), Complexity leadership: Part I: Conceptual foundations. Charlotte, NC: Information Age: 185-224.

Van Manen, M (1990) Researching lived experience: Human science for an action-sensitive pedagogy. Albany: State University of New York Press.

Watson, JB (1924) Behaviorism. New York, NY: Peoples Institute. 
